\title{
Annual Crop Yield Variation, Child Survival and Nutrition among Subsistence Farmers in Burkina Faso
}

Kristine Belesova, Antonio Gasparrini, Ali Sié, Rainer Sauerborn, ${ }^{1}$ and Paul Wilkinson ${ }^{1}$

${ }^{1}$ - These authors share last authorship

Correspondence to Kristine Belesova, Department of Social and Environmental Health Research, London School of Hygiene \& Tropical Medicine, 15-17 Tavistock Place, London WC1H 9SH, UK (e-mail: kristine.belesova@1shtm.ac.uk, tel.: +44 (0) 207612 4847)

Author affiliations: Department of Social and Environmental Health Research, London School of Hygiene \& Tropical Medicine, London, UK (Kristine Belesova, Antonio Gasparrini, and Paul Wilkinson); Centre de Recherche en Santé de Nouna, Nouna, Kossi province, Burkina Faso (Ali Sié); and Institute of Public Health, Heidelberg University, Heidelberg, Germany (Rainer Sauerborn).

This work was supported by the Natural Environment Research Council grant NE/L501979/1.

Conflict of interest: none declared.

Running head: Crop Yield Variation, Child Survival and Nutrition 


\section{LIST OF ABBREVIATIONS}

CI Confidence Interval

FCPI Food Crop Productivity Index

HDSS Health and Demographic Surveillance System

MUAC Middle-Upper Arm Circumference 


\begin{abstract}
Whether year to year variation in crop yields affects the nutrition, health, and survival of subsistence farming populations is relevant to the understanding of the potential impacts of climate change. However, the empirical evidence is limited. We examined the association of child survival with inter-annual variation in food crop yield and middle-upper arm circumference (MUAC) in a subsistence farming population of rural Burkina Faso. The study was of 44,616 children $<5$ years of age included in the Nouna Health and Demographic Surveillance System, 1992-2012, whose survival was analysed in relation to the food crop yield in the year of birth (which ranged from $65 \%$ to $120 \%$ of the period average) and, for a subset of 16,698 children, to MUAC, using shared frailty Cox proportional hazards models. Survival was appreciably worse in children born in years with low yield (fully adjusted hazard ratio of $1.11(95 \%$ confidence interval: $1.02,1.20)$ for a $90^{\text {th }}$ to $10^{\text {th }}$ centile decrease in annual crop yield) and in children with small MUAC (hazard ratio 2.72 (95\% confidence interval: $2.15,3.44$ ) for a $90^{\text {th }}$ to $10^{\text {th }}$ centile decrease in MUAC). These results suggest an adverse impact of variations in crop yields which could increase under climate change.
\end{abstract}

KEYWORDS: agriculture, child mortality, climate change, edible grain, food, malnutrition, survival, undernutrition 
Year to year variation in crop yields has potentially important implications for the nutrition, health and survival of people in subsistence farming populations (1-3). In areas reliant on rain-fed agriculture, such as rural West Africa, the magnitude of these implications may further rise with increased variability in weather and crop yields, as projected under climate change (4).

However, empirical evidence on the associations of survival and nutritional outcomes with crop yield variability is limited. A recent review concluded that current evidence on nutritional impacts of crop yield variability draws on a small number of heterogeneous and methodologically limited studies based on secondary data (2). Most studies on the association of crop yield (or its markers) with measures of undernutrition are cross-sectional (5-9), which limits conclusions on causality of the association and understanding of the impacts of interannual yield variation (2).

A small number of studies have examined the link between proxies of crop yield variation and survival, for example, studies on the association of mortality with a measure of household food security (based on agricultural yield) in Tanzania (10) and with spatial variability of the Normalized Difference Vegetation Index (a measure of the intensity of vegetation cover) in the year of child's birth in Burkina Faso and Mali (11).

This paper examines associations of child survival over first five years of life, nutritional status, measured by middle-upper arm circumference (MUAC), and inter-annual food crop yield variation in a subsistence farming population in rural Burkina Faso, using large longitudinal datasets. Our main focus is on the associations of child survival with (i) variation in annual food crop yield in the year of child's birth and (ii) with MUAC. In addition, we examined whether MUAC (as an outcome) is associated with crop yield variation to explore 
if the association of child survival with crop yield is likely to operate through changes in nutrition (Figure 1).

\section{METHODS}

Study area and population

This study was based on follow up of children in the population of the Nouna Health and Demographic Surveillance System (HDSS) run by the Centre de Recherche en Santé de Nouna. The Nouna HDSS area covers one third of the Kossi province, an area of dry orchard savannah of western Burkina Faso. The single agricultural production season lasts during the rainy season with sowing starting in May/June and the crop harvest in September (12). The local population $(297,183$ in 2009$)$ is almost exclusively subsistence farmers relying on rainfed agriculture, with their livelihoods being susceptible to variations in rainfall (12-14). We assembled the following data:

\section{(1) Mortality/survival}

The study of survival was based on data for 44,616 children less than 5 years of age included in the Nouna HDSS routine data collection for the period 1992-2012. During this period, children were followed-up for vital events and migration every 3 months until 2006 and every 4 months thereafter. We obtained dates of birth and death or in-/out-migration. Individuals born before the start of the study period or outside the Nouna HDSS area were excluded from analysis as were the individuals whose month of birth, death, or migration was missing.

\section{(2) MUAC}

49,056 MUAC measurements were available (from the HDSS surveys) on 25,480 children $<5$ years of age surveyed during the period of January 2009 to October 2014. Of these 20,340 
measurements on 16,698 children were taken over the period January 2009 to December 2012 (i.e., coinciding with the period for which survival data were available). Values of MUAC greater than 5 standard deviations from the mean (i.e., outside the range of 67 to 218 $\mathrm{mm})$ were deemed implausible and excluded from analysis (15-17).

\section{(3) Agricultural yield data}

Data on the annual yield $(\mathrm{kg} / \mathrm{ha})$ of each of the five main food crops in the Kossi province (millet, sorghum, fonio, maize, and rice), collected as a part of the national Annual Agricultural Survey, were obtained from the Agricultural Statistics Service of Burkina Faso for the period of 1992-2014. From these data we computed an annual Food Crop Productivity Index (FCPI). The FCPI represents a weighted average of the yield $(\mathrm{kg} / \mathrm{ha})$ of each of the main food crops (millet, sorghum, maize, fonio, and rice) relative to the period annual mean yield for 1992-2012, expressed as a percentage of the period average. It was calculated as follows:

\section{Food Crop Productivity Index FCPI for year $\mathrm{i}=\sum_{\mathrm{i}} \mathrm{p}_{\mathrm{ij}} * \mathrm{w}_{\mathrm{ij}}$}

where

$p_{\mathrm{ij}}-$ is the yield in year i for crop $\mathrm{j}$ relative (percentage) to its mean yield over the period of $1992-2012$

$w_{i j}-$ is the proportion of the total harvest across the five crop types in year $\mathrm{i}$ from crop $\mathrm{j}$

Rice yield data was missing for the year 1994. The FCPI value for this year was calculated assuming rice harvest proportion in 1994 was zero (minor assumption given the period average rice harvest proportion of only $0.4 \%$ ). Given similar food energy value across the examined crop types (18), kcal expression of the weighting factors for crop-specific yields comprising FCPI here was unnecessary (calculation using energy equivalents leads to occasional decimal point changes only). 
Individual sex, ethnicity, religion, ability to read, familial links, and residence were obtained from the HDSS records. In addition, village-level data on infrastructural characteristics of Nouna HDSS villages (presence of markets, health care facilities, drilled water wells, and the quality of road connection) were obtained from the Centre de Recherche en Santé de Nouna.

The study was conducted following the ethical standards of the Declaration of Helsinki (19) and was approved by the London School of Hygiene and Tropical Medicine Observational Ethics Committee and the Comité Institutionnel d'Ethique du Centre de Recherche en Santé de Nouna. Informed consent was obtained by the Centre de Recherche en Santé de Nouna from all subjects at the time of health and demographic data collection.

Analyses

We carried out three separate analyses:

(i) the association of survival (from birth to 5 years of age) with FCPI using data for 1992-2012,

(ii) the association of survival (to 5 years of age) with MUAC using data for 20092012, and

(iii) the association of MUAC with FCPI using data for 2009-2014 (Figure 1).

The timeframe of each analysis was determined by data availability (Web Table 1).

Child survival was examined by tabulation, Kaplan Meier plots and Cox proportional hazards models with shared frailty specified by village and with age as the analysis time.

Observations of children lost to the follow up before reaching 5 years of age were censored at the date of last contact. 
For analyses of survival in relation to FCPI, survival from birth (to 5 years) was related to the FCPI for the last harvest preceding or at the time of the date of birth (adjusting for the mean FCPI the child experienced since birth till 5 years of age). Separate models were constructed with FCPI fitted (i) as a continuous numerical score (reporting model results as the hazard ratio for a $90^{\text {th }}$ to $10^{\text {th }}$ centile decrease in FCPI) and (ii) as a binary classifier above and below the period average FCPI value.

For survival in relation to MUAC, follow up was from the date of MUAC measurement and again continued to the age of 5 years. MUAC was treated as a time-variant exposure (thus allowing the incorporation of data for multiple MUAC measurements per child where available). Before being included in the Cox models, all MUAC values were 'corrected' for season of measurement using a linear regression model. Separate models were constructed with MUAC measurements fitted (i) as numerical scores (reporting results as the hazard ratio for a $90^{\text {th }}$ to $10^{\text {th }}$ centile decrease in MUAC) and (ii) as a three-value classifier $(\leq 115,115$-, 125- mm).

For both sets (FCPI and MUAC) of survival analyses, results are shown with adjustment for various combinations of potential confounders $(2,11,20,21)$ determined a priori. These confounders were: sex, season of birth, ethnicity, religion, mother's and father's ability to read, semi-rural (Nouna town) vs rural residence (villages), indicators of village infrastructural characteristics (presence of a market, health care facility, drilled water wells, and quality of road connection), a linear term for time trend (year), a binary indicator of the existence of a undernutrition treatment programme. In the case of models of survival in relation to MUAC, we also adjusted for the scale $(\mathrm{mm} v s \mathrm{~cm})$ in which the MUAC measurement was recorded during data collection. 
The association of MUAC with FCPI was examined using multilevel linear regression models constructed with nested random effects at the level of village and individual (to account for repeated MUAC measurements on the same individuals), and using similar combinations of confounders to those indicated above and as shown in the tables. Separate multilevel linear regression models were constructed for FCPI at three time points: FCPI in the year of MUAC measurement (adjusting for the mean FCPI experienced since birth to measurement), year of birth (adjusting for the mean FCPI experienced between 1 and 5 years of age), and the lifetime average FCPI exposure till 5 years of age.

Sensitivity analyses for the association of child survival with MUAC were performed excluding children $<6$ months of age and using MUAC cut-offs of 115 and $125 \mathrm{~mm}$ to detect severe and moderate acute undernutrition (22).

All statistical analyses were performed using Stata 14.1 (College Station, TX: StataCorp LP).

\section{RESULTS}

Characteristics of the study subjects monitored over the period of analysis for survival, 19922012, are given in the Table 1 and Web Table 2. Among the 44,616 children, 4,535 deaths were recorded, representing an average mortality rate of 31.25 deaths per 1,000 person-years at risk.

Characteristics of the 16,698 subjects with MUAC measurements monitored over the period of analysis of 2009-2012 are presented in Web Table 3. Mean MUAC among these subjects was $142(95 \%$ confidence interval (CI): 141,142$) \mathrm{mm} .5 \%$ had MUAC $\leq 115 \mathrm{~mm}$ and $9 \%$ MUAC 115-125 mm. The earliest MUAC measurements were made in the first month of life with $43 \%$ made in the $1^{\text {st }}$ and $21 \%$ between the $1^{\text {st }}$ and $2^{\text {nd }}$ year of life. 
Crop data showed the highest average yield (kg/ha) for maize, followed by rice, sorghum, and millet (Figure 2; Web Table 4). Inter-annual variability in the FCPI was mainly driven by changes in the productivity of millet and sorghum, since on average millet and sorghum together constituted $89 \%$ of the total harvest of all the five food crops in the Kossi province (Web Table 4). Over the 23 years of the study, the FCPI varied from the minimum of $65 \%$ to the maximum of $120 \%$ of the period average, with the $10^{\text {th }}-90^{\text {th }}$ centile interval of $82 \%$ $119 \%$.

\section{Survival}

K-M plots showed mortality risk to be highest in the first 2 to 3 years of age (Figures 3 and 4). Survival was lower among children born in years of below average FCPI than among children born in years of above average FCPI (Figure 3). Results of the Cox regression analyses showed that child survival was associated with FCPI in the year of birth (Table 2) with a decrease in yield from $90^{\text {th }}$ to $10^{\text {th }}$ centile corresponding to hazard ratio of $1.11(95 \%$ CI: $1.02,1.20)$ in the fully adjusted analyses.

Survival was also associated with MUAC measurements (Table 3; Figure 4). A decrease in MUAC from $90^{\text {th }}$ to $10^{\text {th }}$ centile was associated with a hazard ratio of 2.72 (95\% CI: 2.15 , $3.44)$ in the fully adjusted model. For children with MUAC $\leq 115 \mathrm{~mm}$ the hazard ratio was 2.73 (95\% CI: 2.10, 3.55) and with MUAC 115-125 mm 1.94 (95\% CI: 1.53, 2.48), compared to children with MUAC $>125 \mathrm{~mm}$. With the exclusion of children $<6$ months of age the hazard ratio for children with MUAC $<115 \mathrm{~mm}$, representing severe acute undernutrition, increased to 3.60 (95\% CI: 2.30, 5.63) but did not change for children with MUAC 115-125 mm (Web Table 5).

\section{MUAC in relation to FCPI}


Children's MUAC was also related to FCPI in the year of MUAC measurement and to lifetime average FCPI (Table 4), though not with the FCPI in the year of birth. In fully adjusted models, a decrease from $90^{\text {th }}$ to $10^{\text {th }}$ centile in FCPI in the year of measurement was associated with a decrease of $2.62(95 \% \mathrm{CI}: 2.08,3.15) \mathrm{mm}$ in MUAC, and the corresponding figure in relation to lifetime average FCPI was a decrease of 3.81 (95\% CI: 2.89, 4.73) $\mathrm{mm}$.

\section{DISCUSSION}

This study provides new evidence, based on analysis of longitudinal data, of the relationship between child survival, nutrition and annual variation in crop yields in a subsistence farming population of Burkina Faso. The main findings were that child survival was (inversely) associated with food crop yield in the year of birth and with short-term nutritional status, reflected by MUAC, and that MUAC measurements themselves were related to crop yields in the year of measurement and over the child's lifetime (though not with yields in the year of birth). Poor nutrition may thus be at least part mediator of the relationship between low crop yields and survival. It is noteworthy that we did not find clear evidence that MUAC was related to crop yield in the year of birth despite evidence for poorer survival when there is a low yield in the year of birth. This may reflect the relatively long interval between birth and first MUAC measurement for many children (MUAC tends to indicate the nutrition of recent months).

These findings are broadly consistent with previous published research. Such research includes a study which found positive association of childhood survival with spatial variability of food crop yield (approximated by mean Normalized Difference Vegetation Index over the agricultural season) in the year of birth in Mali and Burkina Faso (11), seasonal differences in food availability in Gambia $(23,24)$, and annual rainfall, 
approximating drought conditions, in rural Burkina Faso (21) and India (25). Our findings are also consistent with studies reporting positive association of wasting (anthropometric measure used to determine the same type of undernutrition (acute undernutrition) as MUAC) with the same year Normalized Difference Vegetation Index in Nepal (8), Normalized Difference Vegetation Index in the year of birth in Mali (11), and drought at the time of birth in India (25). Our results also support prior findings of MUAC as a strong predictor of child mortality $(22,26)$.

If interpreted as reflecting causal associations, our results suggest that low food crop yields in the rural population of Burkina Faso limit food availability needed for children's growth and development, posing a risk for subsequent short and medium term health (survival). Of particular concern is the apparent association of low crop yield in the year of birth with childhood survival up to five years of age suggesting a persisting adverse consequence of reduced food availability around the time of, or shortly after, birth.

What our analyses do not clearly distinguish is whether this is most likely to be a consequence of in utero exposures with poor nutrition of the mother leading up to birth, or of poor nutrition during the first year of life. Medical evidence demonstrates that both in utero and early life (first 24 months) undernutrition are associated with long-term health consequences, such as impaired cardiac health (27) and kidney function (28), lower height, higher blood glucose concentrations, increased blood pressure, harmful lipid profiles, and higher chance of mental illness (29,30). Studies examining health status of adult survivors, who were exposed to historical famines in utero or early life in China, Russia, Finland, and Netherlands, observed poorer mental and physical health, manifested by impairments of the central nervous system, higher rates of coronary heart disease, metabolic dysfunction, and antisocial behaviour (31-38). Furthermore, a study on Bangladesh famine following monsoon flooding in 1974 found an increased mortality rate in the cohort of children born during the 
famine, as compared to the cohorts conceived during or after the famine (39). These studies suggest higher frailty of those exposed to food shortages in utero and early life and higher risk of mortality in subsequent life. Such individuals are suggested to be even more vulnerable to later instances of low food availability (40).

\section{Implications}

The principal implication of our findings is that children in the subsistence farming population of Nouna and potentially elsewhere may be vulnerable to reductions in food crop yield, which in areas of rain-fed agriculture is often related to unfavourable weather conditions over the growing season. This is of particular concern in the context of the projected increase in the frequency and severity of droughts and other drivers of increased crop yield variability with further climate change in West Africa and other regions with high prevalence of subsistence rain-fed agriculture $(4,41)$.

Adaptation responses should therefore take account of such potential impacts and incorporate careful nutritional monitoring in households with pregnant mothers, new-borns, and young children, particularly in years with low crop yields. There may be value in considering measures that could protect against low crop yields and their consequences for health, such as early weather warning systems, crop insurance systems, use of drought resistant crops, improvement of irrigation, improved health systems, and others.

\section{Limitations}

First, we acknowledge that because the hazard ratios for survival in relation to FCPI are not large, there is the possibility that our results could be due to residual confounding. It is not clear what extrinsic time-varying factors associated with years of low FCPI could be important as confounders. Direct weather effects (i.e., on mortality as well as on crop yield) 
are a possible alternative explanation for very short-term associations, but not of the results for FCPI in the year of birth affecting later survival.

We used provincial food crop yield records to derive a measure of relative food crop yield variability (FCPI) in our study population of Nouna HDSS, which covers around one third of the province. Despite this approximation, we found strong associations of the relative yield measure with nutritional and mortality outcomes among children $<5$ years of age in this population. With no data on spatial yield variability across the province, we could not use year as an additional indicator variable to control for any potentially confounding temporal factors other than time trend (which we controlled for). Therefore, we explored the possibility of such factors through discussions with the local research centre and context exploration. We identified the establishment of the undernutrition treatment programme as the only potentially confounding temporal factor and controlled for it using a binary indicator variable. Further analysis based on more spatially refined resolution of annual crop yield variability may provide even stronger associations than identified here.

An even stronger associations of survival with MUAC and MUAC with FCPI could be observed if MUAC measurements in our dataset were more equally distributed across seasons; in our data a relatively small number of MUAC measurements were made in the lean season (June-August), when household cereal stocks from the last harvest are running low and proportion of children with low MUAC tends to be higher than in other seasons $(42,43)$.

As indicated above, our finding of no significant association of MUAC with FCPI in the year of birth (as opposed to FCPI in the year of MUAC measurement and lifetime average FCPI) could reflect the long interval between birth and first MUAC measurement. But it may also reflect a bias that fewer children with low MUAC may survive to have a MUAC 
measurement in a low FCPI year compared with a high FCPI year. This bias cannot be directly quantified from our data but among those who had MUAC measurements in the first year, the mean MUAC was 126 (95\% CI: 123, 129) in those who died before 12 months and 135 (95\% CI: 134, 136) in those who survived to 12 months, and mortality rates of 30 vs 27 deaths per 1,000 person in children born in years with below and above average FCPI respectively.

The analysed data series were sufficient to examine each association of our interest separately. The data series did not have a sufficient temporal overlap to permit formal mediation analysis and establish the extent to which the association of low crop yields with child survival was mediated by low MUAC as opposed to other processes.

\section{CONCLUSION}

The survival of children $<5$ years of age in the Nouna HDSS population was related to the food crop yield in their year of birth and to their nutritional status, as measured by MUAC. Children's MUAC was also associated with the relative yield of the preceding harvest and average yield over children's lifetime.

Our results suggest that child nutrition and survival in this and possibly similar subsistence farming populations are vulnerable to inter-annual variation in food crop yield. This observation may become more significant with the increased variability in crop yields, suggested under climate change. Methods of protecting against low crop yields integrated with household nutritional monitoring could help to reduce such adverse impacts. 


\section{ACKNOWLEDGEMENTS}

Author affiliations: Department of Social and Environmental Health Research, London

School of Hygiene \& Tropical Medicine, London, United Kingdom (Kristine Belesova, Antonio Gasparrini, and Paul Wilkinson); Centre de Recherche en Santé de Nouna, Nouna, Kossi province, Burkina Faso (Ali Sié); Institute of Public Health, Heidelberg University, Heidelberg, Germany (Rainer Sauerborn).

Authorship: KB designed the study with advisory input from PW and RS; AS provided data; $\mathrm{KB}$ cleaned and prepared data; KB analysed data with advice and review by PW and AG; KB drafted the paper incorporating editorial changes and comments from other authors. All authors have reviewed and approved the submitted manuscript.

Source of funding: This work was supported by the Natural Environment Research Council (grant number NE/L501979/1).

Authors would like to thank Prof. Ben Armstrong and Mr. Francesco Sera for advice on statistical analyses, staff of the Centre de Recherche en Santé de Nouna, who are responsible for the collection and provision of the data used in this study, Mr. Moubassira Kagoné, Mr. Pascal Zabré, Dr. Issouf Traoré, and Mr. Cheik Bagagnan for explanations on the data structure, and Mr. Abroulaye Sanfo for assistance in requesting national agricultural production data. We would also like to thank to the Environmental Health Research Group of the London School of Hygiene and Tropical Medicine for helpful comments on results of this study. Conflict of interest: none declared.

Correspondence to Kristine Belesova, Department of Social and Environmental Health Research, London School of Hygiene \& Tropical Medicine, 15-17 Tavistock Place, London WC1H 9SH, UK.

(e-mail: Kristine.belesova@1shtm.ac.uk) tel.: +44 (0) 2076124847 


\section{REFERENCES}

1. Brown ME, Funk CC. Food Security Under Climate Change. Science. 2008;319(5863):580-581.

2. Phalkey RK, Aranda-Jan C, Marx S, et al. Systematic review of current efforts to quantify the impacts of climate change on undernutrition. Proc. Natl. Acad. Sci. 2015;112(33):E4522-E4529.

3. Stanke C, Kerac M, Prudhomme C, et al. Health Effects of Drought: a Systematic Review of the Evidence. PLOS Curr. Disasters. 2013;1-38.

4. Intergovernmental Panel on Climate Change (IPCC). Managing the Risks of Extreme Events and Disasters to Advance Climate Change Adaptation (SREX). A Special Report of Working Groups I and II of the Intergovernmental Panel on Climate Change. $2012 ; 1-594$.

5. Ghattas H, Barbour JM, Nord M, et al. Household food security is associated with agricultural livelihoods and diet quality in a marginalized community of rural Bedouins in Lebanon. J. Nutr. 2013;143(13):1666-1671.

6. Shack KW, Grivetti LE, Dewey KG. Cash cropping, subsistence agriculture, and nutritional status among mothers and children in lowland Papua New Guinea. Soc. Sci. Med. 1990;31(1):61-68.

7. Kaufmann S. The nutrition situation in Northern Laos - determinants of malnutrition and changes after four years of intensive interventions [dissertation]. Gissen: Justus Liebig University Giessen; 2008.

8. Shively G, Sununtnasuk C, Brown M. Measuring the Links Between Agriculture and Child Health in Nepal. Nutr. CRSP Res. Brief. Pap. No. 10. 
http://dl.tufts.edu/bookreader/tufts:16389\#page/9/mode/2up. Published 2012. Accessed May 24, 2017.

9. Apodaca C. Preventing child malnutrition: Health and agriculture as determinants of child malnutrition. J. Child. Poverty. 2008;14(1):21-40.

10. Alba S, Nathan R, Schulze A, et al. Child mortality patterns in rural Tanzania: An observational study on the impact of malaria control interventions. Int. J. Epidemiol. 2014;43(1):204-215

11. Johnson K, Brown ME. Environmental risk factors and child nutritional status and survival in a context of climate variability and change. Appl. Geogr. 2014;54(2014):209-221.

12. Dabat M, Zongo I, Kiendrebeogo R. Etude sur les relations entre marchés et sécurité alimentaire au Burkina Faso. World Food Program. 2012.

13. Indepth. Nouna HDSS, Burkina Faso. http://www.indepth-network.org/Profiles/Nouna HDSS.pdf. Published 2009. Accessed April 12, 2016.

14. INSD (Institut National de la Statistique et de la Démographie). Population et densité par région et province. http://www.insd.bf/n/contenu/Tableaux/T0316.htm.

Ouagadougou: INSD. Updated 2013. Accessed March 4, 2016.

15. Myatt M. Plausible/extreme values for MUAC. http://www.ennet.org/question/233.aspx. Published July 16, 2010. Accessed February 13, 2017.

16. Ralston ME, Myatt MA. Weight estimation tool for children aged 6 to 59 months in limited-resource settings. PLoS One. 2016;11(8):e0159260.

17. Mwangome MK, Fegan G, Fulford T, et al. Mid-upper arm circumference at age of routine infant vaccination to identify infants at elevated risk of death: a retrospective 
cohort study in the Gambia. Bull. World Health Organ. 2012;90(12):887-894.

18. Stadlmayr B, Charrondiere UR, Enujiugha VN, et al. West African food composition table. Rome: FAO; 2012.

19. 41st World Medical Assembly. Declaration of Helsinki: recommendations guiding physicians in biomedical research involving human subjects. Bull Pan Am Heal. Organ. 1990;24:606-609.

20. Benzler J, Sauerborn R. Rapid risk household screening by neonatal arm circumference: results from a cohort study in rural Burkina Faso. Trop. Med. Int. Health. 1998;3(12):962-974.

21. Dos Santos S, Henry S. Rainfall variation as a factor in child survival in rural Burkina Faso: The benefit of an event-history analysis. Popul. Space Place. 2008;14(1):1-20.

22. Laillou A, Prak S, De Groot R, et al. Optimal screening of children with acute malnutrition requires a change in current WHO guidelines as MUAC and WHZ identify different patient groups. PLoS One. 2014;9(7):9-15.

23. Moore SE, Fulford AJC, Streatfield PK, et al. Comparative analysis of patterns of survival by season of birth in rural Bangladeshi and Gambian populations. Int. J. Epidemiol. 2004;33(1):137-143.

24. Moore SE, Cole TJ, Poskitt EME, et al. Season of birth predicts mortality in rural Gambia. Nature. 1997;388(6641):434.

25. Kumar S, Molitor R, Vollmer S. Children of Drought: Rainfall Shocks and Early Child Health in Rural India. Popul. Dev. Rev. 2016;42(1):53-68.

26. Pelletier DL. The relationship between child anthropometry and mortality in developing countries: implications for policy, programs and future research. 
1994;124:2047S-2081S.

27. Hoet JJ, Hanson MA. Intrauterine nutrition: Its importance during critical periods for cardiovascular and endocrine development. J. Physiol. 1999;514(3):617-627.

28. Brenner BM, Chertow GM. Congenital oligonephropathy and the etiology of adult hypertension and progressive renal injury. Am. J. Kidney Dis. 1994;23(2):171-175.

29. Victora CG, Adair L, Fall C, et al. Maternal and child undernutrition: consequences for adult health and human capital. Lancet. 2008;371(9609):340-357.

30. Walker SP, Wachs TD, Gardner JM, et al. Child development: risk factors for adverse outcomes in developing countries. Lancet. 2007;369(9556):145-157.

31. St Clair D, Xu M, Wang P, et al. Rates of adult schizophrenia following prenatal exposure to the Chinese famine of 1959-1961. J. Am. Med. Assoc. 2005;294(5):557562.

32. Luo Z, Mu R, Zhang X. Famine and overweight in China. Rev. Agric. Econ. 2006;28(3):296-304.

33. Stanner SA, Bulmer K, Andrès C, et al. Does malnutrition in utero determine diabetes and coronary heart disease in adulthood? Results from the Leningrad siege study, a cross sectional study. BMJ. 1997;315(7119):1342-1348.

34. Stanner SA, Yudkin JS. Fetal programming and the Leningrad Siege study. Twin Res. 2001;4(5):287-292.

35. Kannisto V, Christensen K, Vaupel JW. No increased mortality in later life for cohorts born during famine. Am. J. Epidemiol. 1997;145(11):987-994.

36. Ravelli ACJ, van der Meulen JHP, Osmond C, et al. Obesity at the age of 50y in men 
and women exposed to famine prenatally. Am. J. Clin. Nutr. 1999;70:811-816.

37. Huang C, Li Z, Wang M, et al. Early life exposure to the 1959-1961 Chinese famine has long-term health consequences. J. Nutr. 2010;140(10):1874-1878.

38. Chen Y, Zhou LA. The long-term health and economic consequences of the 1959-1961 famine in China. J. Health Econ. 2007;26(4):659-681.

39. Razzaque A, Alam N, Wai L, et al. Sustained effects of the 1974-75 famine on infant and child mortality in a rural area of Bangladesh. Popul. Stud. A J. Demogr. 1990;44(1):145-154.

40. Hayward AD, Rickard IJ, Lummaa V. Influence of early-life nutrition on mortality and reproductive success during a subsequent famine in a preindustrial population. Proc. Natl. Acad. Sci. 2013;110(34):13886-13891.

41. Ministaire de L'Environnement et du Cadre de Vie: Secretariat Permanent du Conseil National pour L'Environnement et le Developpement Durable. Programme d'Action National d'Adaptation a le Variabilite et aux Changements Climatiques (PANA du Burkina Burkina Faso). Ouagadougou: Ministaire de L'Environnement et du Cadre de Vie: Secretariat Permanent du Conseil National pour L'Environnement et le Developpement Durable; 2007.

42. FEWS NET. Seasonal Calendar: Typical Year. http://www.fews.net/westafrica/burkina-faso/seasonal-calendar/december-2013. Published December 2013. Accessed January 1, 2016.

43. Beiersmann $\mathrm{C}$, Bountogo M, Tiendrébeogo J, et al. Malnutrition in young children of rural Burkina Faso: comparison of survey data from 1999 with 2009. Trop. Med. Int. Health. 2012;17(6):715-721. 


\section{TABLES}

Table 1. Number of Children, Deaths, Person-Years, and Mortality Rate by Individual Characteristics, Nouna HDSS, Burkina Faso, 1992-2012 ( $n=44,616$ Children <5 Years of Age)

\begin{tabular}{|c|c|c|c|c|c|}
\hline Factors & $\begin{array}{r}\text { No. of } \\
\text { children }\end{array}$ & $\begin{array}{r}\% \text { of } \\
\text { children }\end{array}$ & Deaths & $\begin{array}{r}\text { P-y at } \\
\text { risk }^{\mathbf{a}}\end{array}$ & $\begin{array}{r}\text { Mortality } \\
\text { rates per } \\
1,000 \mathrm{p}-\mathrm{y}\end{array}$ \\
\hline \multicolumn{6}{|l|}{ Age } \\
\hline $0-$ & 44,616 & 100 & 2,069 & 40,305 & 51.33 \\
\hline $1-$ & 37,040 & 83 & 1,295 & 33,171 & 39.04 \\
\hline $2-$ & 30,939 & 69 & 757 & 27,700 & 27.33 \\
\hline $3-$ & 26,246 & 59 & 272 & 23,625 & 11.51 \\
\hline $4-$ & 22,613 & 51 & 142 & 20,306 & 6.99 \\
\hline \multicolumn{6}{|l|}{ Sex } \\
\hline male & 22,358 & 50 & 2,395 & 72,806 & 32.90 \\
\hline female & 22,258 & 50 & 2,140 & 72,301 & 29.60 \\
\hline \multicolumn{6}{|l|}{ Ethnicity } \\
\hline Bwamu & 11,385 & 28 & 1,072 & 37,409 & 28.66 \\
\hline Dafing & 17,426 & 39 & 1,968 & 56,617 & 34.76 \\
\hline Mossi & 7,938 & 18 & 683 & 26,179 & 26.09 \\
\hline Phole & 4,322 & 7 & 517 & 13,656 & 37.86 \\
\hline Samo & 2,676 & 6 & 221 & 8,664 & 25.51 \\
\hline other & 822 & 2 & 67 & 2,466 & 27.17 \\
\hline unclassified & 47 & 0.1 & 7 & 116 & 60.36 \\
\hline \multicolumn{6}{|l|}{ Religion } \\
\hline Animist & 2,395 & 5 & 330 & 8,121 & 40.63 \\
\hline Catholic & 11,893 & 27 & 1,022 & 38,802 & 26.34 \\
\hline Muslim & 28,195 & 63 & 3,007 & 91,166 & 32.98 \\
\hline Protestant & 1,997 & 5 & 157 & 6,646 & 23.62 \\
\hline other & 78 & 0.2 & 4 & 229 & 17.48 \\
\hline unclassified & 58 & 0.1 & 15 & 143 & 105.19 \\
\hline \multicolumn{6}{|l|}{ Mother's ability to read } \\
\hline unable & 28,245 & 63 & 2,952 & 99,465 & 29.68 \\
\hline with difficulty & 1,555 & 4 & 115 & 5,252 & 21.90 \\
\hline easily & 1,531 & 3 & 89 & 4,830 & 18.43 \\
\hline unclassified & 13,285 & 30 & 1,379 & 35,560 & 38.78 \\
\hline \multicolumn{6}{|l|}{ Father's ability to read } \\
\hline unable & 25,153 & 56 & 2,616 & 85,860 & 30.47 \\
\hline with difficulty & 3,437 & 8 & 288 & 12,119 & 23.77 \\
\hline easily & 3,074 & 7 & 207 & 10,522 & 19.67 \\
\hline unclassified & 12,952 & 29 & 1,424 & 36,607 & 38.90 \\
\hline \multicolumn{6}{|l|}{ Season at birth } \\
\hline Sep-Nov & 12,052 & 27 & 1,355 & 39,645 & 34.18 \\
\hline Dec-Feb & 10,432 & 23 & 1,092 & 34,173 & 31.96 \\
\hline Mar-May & 11,008 & 25 & 1,022 & 35,815 & 28.54 \\
\hline Jun-Aug & 11,124 & 25 & 1,066 & 35,475 & 30.05 \\
\hline \multicolumn{6}{|c|}{ Season of exit from the follow up } \\
\hline Sep-Nov & 7,517 & 17 & 1,389 & 27,360 & 50.77 \\
\hline Dec-Feb & 7,356 & 17 & 1,102 & 27,103 & 40.66 \\
\hline Mar-May & 8,689 & 20 & 935 & 32,978 & 28.35 \\
\hline Jun-Aug & 21,054 & 47 & 1,109 & 57,667 & 19.23 \\
\hline
\end{tabular}

Abbreviations: HDSS, health and demographic surveillance system; P-y, person-years at risk a Person-years at risk here are presented since birth till the end of the follow up. 
Table 2. Results of Cox Regression Analysis: Child Survival to 5 Years of Age in Relation to Food Crop Yield in the Year of Birth in Nouna HDSS, Burkina Faso, 1992-2012 ( $n=44,616$ Children)

\begin{tabular}{|c|c|c|}
\hline $\begin{array}{l}\text { Models }^{\mathrm{a}} \text { with different combinations of fixed } \\
\text { effect adjustments and exposure specification }\end{array}$ & $\begin{array}{l}\text { Hazard ratio for all- } \\
\text { cause mortality }\end{array}$ & $95 \% \mathrm{CI}$ \\
\hline \multicolumn{3}{|l|}{ Model $1^{\mathrm{b}}$} \\
\hline$\geq$ period mean $\mathrm{FCPI}^{\mathrm{c}}$ & 1 & Referent \\
\hline$<$ period mean FCPI & 1.23 & $1.15,1.31$ \\
\hline$\Delta 90-10$ FCPI $^{\mathrm{d}}$ & 1.15 & $1.07,1.23$ \\
\hline \multicolumn{3}{|l|}{ Model $2^{\mathrm{e}}$} \\
\hline$\geq$ period mean $\mathrm{FCPI}^{\mathrm{c}}$ & 1 & Referent \\
\hline$<$ period mean FCPI & 1.12 & $1.04,1.20$ \\
\hline$\Delta 90-10 \mathrm{p} \mathrm{FCPI}^{\mathrm{d}}$ & 1.12 & $1.03,1.21$ \\
\hline \multicolumn{3}{|l|}{ Model $3^{\mathrm{f}}$} \\
\hline$\geq$ period mean $\mathrm{FCPI}^{\mathrm{c}}$ & 1 & Referent \\
\hline$<$ period mean FCPI & 1.11 & $1.03,1.18$ \\
\hline$\Delta 90-10 \mathrm{p} \mathrm{FCPI}^{\mathrm{d}}$ & 1.11 & $1.02,1.20$ \\
\hline \multicolumn{3}{|l|}{ Model $4^{\mathrm{g}}$} \\
\hline$\geq$ period mean $\mathrm{FCPI}^{\mathrm{c}}$ & 1 & Referent \\
\hline$<$ period mean FCPI & 1.10 & $1.03,1.18$ \\
\hline$\Delta 90-10$ FCPI $^{\mathrm{d}}$ & 1.11 & $1.02,1.20$ \\
\hline
\end{tabular}

Abbreviations: CI, confidence interval; FCPI, food crop productivity index; 90-10p, a decrease from $90^{\text {th }}$ to $10^{\text {th }}$ centile.

${ }^{a}$ These are shared frailty Cox proportional hazard models with age used as the analysis time and shared frailty specified by village. Therefore, random effects at the village level are adjusted for in all of the presented models.

${ }^{\mathrm{b}}$ Model 1 had no fixed effect adjustments.

${ }^{\mathrm{c}}$ Baseline for the hazard ratio associated with below period average FCPI.

${ }^{\mathrm{d}}$ Obtained from modelling with FCPI as a continuous variable.

${ }^{\mathrm{e}}$ Model 2 was adjusted for the presence of undernutrition treatment programme, time trend, mean FCPI exposure after the child's year of birth till the age of 5 years.

${ }^{\mathrm{f}}$ Model 3, in addition to the adjustments of the model 2, was adjusted for season of birth, sex, ethnicity, religion, mother's and father's ability to read.

${ }^{\mathrm{g}}$ Model 4, in addition to the adjustments of the model 3, was adjusted for the presence of a market, health care facility, drilled wells, road quality, semi-rural vs rural residence. 
Table 3. Results of Cox Regression Analysis: Child Survival to 5 Years of Age in Relation to the Nutritional Status, as Measured by MUAC, in Nouna HDSS, Burkina Faso, 2009-2012 (n = 16,698 Children, 18,511 MUAC Measurements)

\begin{tabular}{|c|c|c|}
\hline $\begin{array}{l}\text { Models }{ }^{\text {a }} \text { with different sets of fixed effect } \\
\text { adjustments and exposure specification }\end{array}$ & $\begin{array}{l}\text { Hazard ratio for all-cause } \\
\text { mortality }\end{array}$ & $95 \% \mathrm{CI}$ \\
\hline \multicolumn{3}{|l|}{ Model $1^{\mathrm{b}}$} \\
\hline MUAC $>125 \mathrm{~mm}^{\mathrm{c}}$ & 1 & Referent \\
\hline MUAC $>115-\leq 125 \mathrm{~mm}$ & 2.10 & $1.65,2.67$ \\
\hline MUAC $\leq 115 \mathrm{~mm}$ & 3.05 & $2.36,3.96$ \\
\hline$\Delta 90-10 \mathrm{p} \mathrm{MUAC}^{\mathrm{d}}$ & 3.04 & $2.42,3.80$ \\
\hline \multicolumn{3}{|l|}{ Model $2^{\mathrm{e}}$} \\
\hline MUAC $>125 \mathrm{~mm}^{\mathrm{c}}$ & 1 & Referent \\
\hline MUAC $>115-\leq 125 \mathrm{~mm}$ & 1.92 & $1.51,2.44$ \\
\hline MUAC $\leq 115 \mathrm{~mm}$ & 2.71 & $2.09,3.52$ \\
\hline$\Delta 90-10$ p MUAC $^{\mathrm{d}}$ & 2.66 & $2.10,3.36$ \\
\hline \multicolumn{3}{|l|}{ Model $3^{\mathrm{f}}$} \\
\hline MUAC $>125 \mathrm{~mm}^{\mathrm{c}}$ & 1 & Referent \\
\hline MUAC $>115-\leq 125 \mathrm{~mm}$ & 1.94 & $1.52,2.46$ \\
\hline MUAC $\leq 115 \mathrm{~mm}$ & 2.73 & $2.10,3.56$ \\
\hline$\Delta 90-10$ p MUAC $^{\mathrm{d}}$ & 2.70 & $2.13,3.42$ \\
\hline \multicolumn{3}{|l|}{ Model $4^{\mathrm{g}}$} \\
\hline MUAC $>125 \mathrm{~mm}^{\mathrm{c}}$ & 1 & Referent \\
\hline MUAC $>115-\leq 125 \mathrm{~mm}$ & 1.94 & $1.53,2.48$ \\
\hline MUAC $\leq 115 \mathrm{~mm}$ & 2.73 & $2.10,3.55$ \\
\hline$\Delta 90-10 \mathrm{p} \mathrm{MUAC}^{\mathrm{d}}$ & 2.72 & $2.15,3.44$ \\
\hline
\end{tabular}

Abbreviations: CI, confidence interval; MUAC, middle-upper arm circumference; $90-10 \mathrm{p}$, a decrease from $90^{\text {th }}$ to $10^{\text {th }}$ centile.

${ }^{a}$ These are shared frailty Cox proportional hazard models with age used as the analysis time and shared frailty specified by village. Therefore, random effects at the village level are adjusted for in all of the presented models.

${ }^{\mathrm{b}}$ Model 1 had no fixed effect adjustments.

${ }^{\mathrm{c}}$ Baseline for the hazard ratio associated with MUAC $<115 \mathrm{~mm}$ and MUAC of $115-125 \mathrm{~mm}$.

${ }^{\mathrm{d}}$ Obtained from modelling with MUAC as a continuous variable.

${ }^{\mathrm{e}}$ Model 2 was adjusted for presence of undernutrition treatment programme, time trend, MUAC measurement scale.

${ }^{\mathrm{f}}$ Model 3, in addition to the adjustments of the model 2, was adjusted for season of birth, sex, ethnicity, religion, mother's and father's ability to read.

${ }^{\mathrm{g}}$ Model 4, in addition to the adjustments of the model 3, was adjusted for the presence of a market, health care facility, drilled wells, road quality, semi-rural $v s$ rural residence. 
Table 4. Results of Multilevel Linear Regression Analysis: Decrease in Children's MUAC $(\mathrm{mm})$ Associated With a Reduction in Food Crop Yield in Nouna HDSS, Burkina Faso, 2009-2014 $(n=49,056$ Children <5 Years of Age)

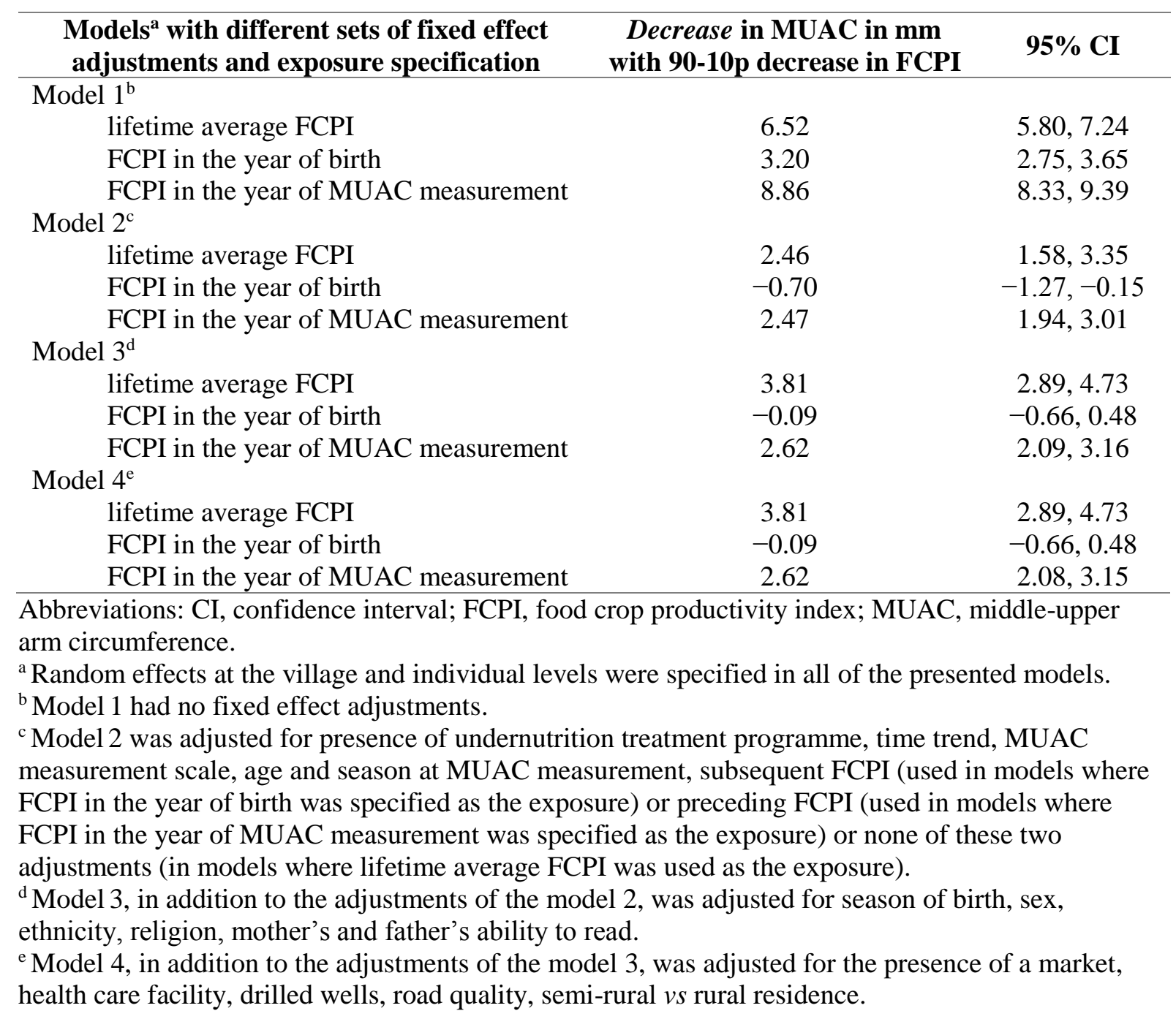




\section{FIGURE LEGENDS}

Figure 1. A conceptual map of the associations between food crop yield, nutritional status, and mortality examined in this paper. Abbreviations: FCPI, food crop productivity index; MUAC, middle-upper arm circumference

Figure 2. Time series of the FCPI (A) and annual yield of each individual crop comprising the FCPI (B) in the Kossi Province, Burkina Faso, 1992-2014. Abbreviations: FCPI, food crop productivity index

Figure 3. Kaplan-Meyer plot of survival probability among children $<5$ years of age in relation to the FCPI in the year of birth in Nouna HDSS, Burkina Faso, 1992-2012 (follow up starts on the date of birth, age is used as analysis time scale). Abbreviations: CI, confidence interval; FCPI, food crop productivity index

Figure 4. Kaplan-Meyer plot of survival probability among children $<5$ years of age in relation to the nutritional status, as measured by MUAC, in Nouna HDSS, Burkina Faso, 2009-2012 (follow up starts on the date of MUAC measurement, age is used as analysis time). Abbreviations: CI, confidence interval; MUAC, middle-upper arm circumference 


\section{SUPPLEMENTARY MATERIAL}

EMS.docx Supplementary material presenting (1) structure of the analysed datasets, (2) number of villages, child deaths, person-years, and mortality rate by village characteristics, Nouna HDSS, Burkina Faso, 1992-2012 (3) number of MUAC measurements, deaths, person-years, and mortality rate by selected individual characteristics, Nouna HDSS, Burkina Faso, 2009-2012, (4) characteristics of crop production variability in the Kossi Province, 1992-2014, and (5) results of sensitivity analysis results for the survival-MUAC Cox models applied to observations within the age interval of 6 months to 5 years. 